\title{
Using Student Survey Data to Build Campus Collaborations
}

\author{
Elizabeth Edwards and Rebecca Starkey \\ The University of Chicago Library, USA
}

\section{Introduction}

Since 2004, the University of Chicago Library has sought to understand the research, teaching, and learning needs of its users through periodic surveys of its campus stakeholders. This paper presents the findings of the library's 2017 Survey of Undergraduates and explores how a shift in focus of the survey program from measuring patron satisfaction to understanding student needs provided the library with new ways to make use of survey data for strategic communication with campus partners, particularly around the development of student research skills and opportunities.

\section{Library Survey Program, 2004-2013}

The University of Chicago Library's use of LibQUAL+ in 2004 and 2007 provided the foundation for its survey program by helping establish baselines and benchmarks for library collections, services, and spaces based on feedback from a sampling of students and faculty. From 2010-2013, the library built on the findings of the two LibQUAL+ projects by surveying, in turn, graduate students, undergraduates, and faculty using locally-developed instruments that explored user satisfaction while posing more specific questions about current and future services. Findings from these institution-specific surveys informed the development of policies, services, and strategic initiatives, but proved to be of limited use in communicating with the campus or other external stakeholders.

\section{Ithaka S+R Surveys, 2015-2017}

Beginning in 2015, the library changed its approach to its survey program by partnering with Ithaka $S+R$ to administer their student survey first to all enrolled graduate and professional school students, then to all enrolled undergraduates two years later. Unlike the library's previous surveys, which focused on the library itself, the Ithaka $\mathrm{S}+\mathrm{R}$ student instrument is situated as a survey about the experiences, needs, and perceptions of the student, with modules exploring higher education objectives, research and teaching practices, and the role of the library. As a result, responses to these surveys provided insight into a range of student experiences and needs that might not otherwise have been expressed to or heard by the library, and resulted in findings that could be used by both the library and its campus partners.

\section{Analysis of the 2017 Survey of Undergraduates}

For LibQUAL+ and the locally developed surveys, the University of Chicago Library's analysis and reporting focused on generating high-level summaries for library administration. Staff survey teams were directed to describe broad themes, rather than identify areas for action. Once the survey team had completed its analysis and reporting, library administration would conduct their own analysis, reviewing the previously-identified themes in order to assign action items. This second phase of analysis was not incorporated into survey reporting.

The survey team produced a similar high-level summary of the 2015 Survey of Graduate and Professional School Students, but it proved to not be useful for decision-making, in part because the challenges identified were not uniquely within the purview of the library. As a result, the 2017 survey team centered their reporting on emergent themes, specifically research skills and opportunities, the impact of library instruction, and the use of the library's physical spaces, rather than trying to generate a high-level summary that could not hope to represent the richness of the data. This thematic approach to reporting resulted in the development of compelling messages for a variety of audiences. 


\section{Findings of the 2017 Survey of Undergraduates}

Undergraduates hope but often fail to have opportunities to conduct original research.

While the majority of undergraduate respondents indicated that it is important to have had the opportunity to collaborate on research projects with professors or advisors, less than half of respondents-to both student surveys-reported having had an opportunity to do so. Survey responses additionally confirm the perception that undergraduates are not often assigned original research; in fact, the most frequently assigned types of work are problem sets, which are regularly assigned to $64 \%$ of respondents, as well as responses to assigned readings, regularly assigned to $57 \%$ of respondents. Although less than $40 \%$ of undergraduate respondents in their fourth year reported being assigned research papers, the majority of undergraduate respondents indicated that it is important to them to acquire nearly all research skills explored in this survey.

Undergraduates feel relatively confident in their research and writing skills.

Nearly half of undergraduate respondents rated their abilities on common research tasks as 'good' or 'very good':

- Synthesizing or incorporating academic information into research projects (48\%)

- Evaluating academic sources of information (47\%)

- Writing according to academic or discipline-specific standards (47\%)

- Locating academic sources of information (46\%)

Respondents were particularly confident in their ability to use information ethically (61\%).

Increasing confidence in these skills positively correlates with time at the university, and respondents with declared majors were consistently more confident in their skills than those who had not declared a major. Despite the high levels of confidence in search skills expressed, a plurality of undergraduate respondents (43\%) reported starting their most recent research project by using a general search engine such as Google.

Undergraduates report frequent use of library spaces.

Ninety-three percent of undergraduate respondents indicated that it is very or extremely useful that the library makes study space available. In fact, $88 \%$ of undergraduate respondents visit the library at least weekly, a stunning number confirmed by entry control logs that, in early 2018, indicated that only one currently-enrolled undergraduate had not visited the library. Eighty percent of respondents reported staying for at least an hour when they visit.

Undergraduates do more than just "hang out" at the library.

The majority of undergraduate respondents visit the library at least weekly to work on a paper or assignment (62\%). More than two-thirds of respondents visit at least quarterly to work on a paper or assignment (93\%); study for an exam (87\%); or work or study with a group of two or more people, but not on a group project (81\%).

Undergraduates benefit from library collections.

Eight-nine percent of undergraduate respondents feel that it is very or extremely useful that the library "pays for resources that I need for my coursework or research projects, from academic journals to books to electronic databases," and 78\% place the same value on the library's provision of its e-reserves system. The majority of respondents visit at least quarterly to use an online (64\%) or physical (55\%) resource. 


\section{Undergraduate research skills improve with library instruction.}

Undergraduate respondents' self-assessments mirror the perceptions of graduate student respondents with teaching responsibilities, only $13 \%$ of whom disagreed with the assertion that their students had poor research skills. However, both recent student surveys demonstrated that it is not clear who should have primary responsibility for supporting the development of these skills. Undergraduate respondents generally perceive the development of research skills to be the responsibility of faculty members rather than librarians, while graduate students with teaching responsibilities indicated that responsibility for developing research skills should fall first to the student, then their instructor, and then the library.

While a minority of respondents expect the library to have responsibility for the development of student research skills, survey responses clearly indicate that library instruction has an impact in this area. Undergraduate respondents who received library instruction-in any form-consistently gave a higher rating to their current research skills than those who did not receive instruction. In particular, respondents who received instruction were more likely to rate as 'good' their skills in synthesizing or incorporating academic information into research projects, locating academic sources of information, and situating research projects within the existing literature. Respondents who received instruction were less likely to start their research from a general search engine than respondents who did not receive instruction; they were also more likely to start their research from an academic search engine or from the library's website.

\section{Building Campus Partnerships}

The new approach to survey analysis, reporting, and communication introduced with the 2017 Survey of Undergraduates facilitated more timely and agile use of survey findings with both internal and external audiences. Presentations and updates focused on the survey's themes were given at the library's monthly allstaff meeting. Shorter reports and talking points, distributed via the library's intranet, allowed library staff to engage in conversations with a wider range of campus partners by focusing on issues that broadly impact undergraduates and exploring areas of shared responsibility. By shifting its focus to the students' challenges rather than the library's existing solutions and historical strengths, the library was able to expand outreach broadly to groups on campus that support undergraduate outreach, research, and learning.

\section{Library Student Advisory Group}

The Library Student Advisory Group (LSAG) has served as a crucial sounding board for the library's survey program. Advice from the group's undergraduate and graduate student members shaped aspects of the promotion, analysis, and reporting for both Ithaka S+R surveys. In return, this group was the first external audience for the findings of both survey projects, providing an opportunity for the survey team to be held accountable by the project's participants by seeking their input on both the validity of the project's findings as well as the efficacy of the messages the library intended to communicate to other campus stakeholders.

Two themes from the 2017 Survey of Undergraduates seemed to be most appropriate for this audience: the use of the library's spaces and services, and the impact of library instruction on student learning. LSAG had previously advised the survey team to explore possible relationships between campus residential housing and use of aspects of the library, so presentations to this group highlighted the response rates by campus housing affiliation, and confirmed that participants tended to prefer the campus library closest to their residence hall, the only meaningful difference in use or behavior noted during analysis by residential location.

Having reported back on the aspects of the project directly informed by the group's input, the survey team also presented LSAG with specific areas of concern that had emerged from the data in order to get feedback on the library's considered path of action. For example, survey responses echoed longstanding concerns about the availability of a quiet twenty-four hour study space. In response, the library conducted interviews with users of its all night study space in order to develop a more complete understanding of the problem. These data and possible next steps were shared with LSAG by a member of the library administration in 
order to determine whether the library's potential solutions seemed reasonable to those who had expressed this need.

The survey team also shared the findings related to student research skills and opportunities. Both topics seemed to resonate with LSAG members based on their experiences as students and instructors, though they seemed less impressed by the findings that indicated the impact of library instruction. Observing the varied levels of engagement was informative as the library and the survey team prepared to take the project's findings to other campus audiences.

\section{Chicago Center for Teaching}

The Chicago Center for Teaching ${ }^{1}$ (CCT) supports faculty and graduate student instructors by providing instructional resources, pedagogical training, and professional development opportunities. While the University of Chicago Library had worked with the CCT in the past, this partnership had been limited to a few isolated workshops on assignment design. The findings of the 2015 and 2017 surveys related to the development of student research skills created an opportunity to build on this historical relationship in hopes of providing more systematic support for student learning in these areas.

Outreach by library administration to the CCT resulted in a series of meetings, first with the CCT's executive director, then with other CCT staff members. In these meetings, library staff highlighted the ambiguity expressed by both undergraduate and graduate respondents with regards to the development of research skills. This message was appropriate for several reasons. First, it acknowledged that while students enter the university feeling confident in their research skills, both the CCT and the library recognize that those skills need to be expanded and refined in order for students to be prepared to do undergraduate and graduate level work. Second, it demonstrated that graduate student instructors-the CCT's primary audience-believed that students themselves are responsible for developing their own research skills, rather than their instructors or the library. Finally, it provided an opportunity for the library to demonstrate-with data-that the instruction it provides has a positive impact on students' confidence in their research skills.

The library approached these conversations with the hope of identifying opportunities to collaborate with CCT staff around the development of student research skills. The most immediate outcome of these conversations was the formation of a quarterly "teaching talk" hosted by the library with CCT staff and other campus units that support academic technologies and instructional design. While it remains to be seen whether these conversations will yield more instructional opportunities for the library (for example, more invitations to collaborate on the development of assignments or course-integrated instruction), they have provided important opportunities to challenge perceptions of the library and its role in supporting student learning.

\section{Center for Research and Fellowships}

Another partner identified for outreach using survey data was the College's Center for Research and Fellowships (CCRF). ${ }^{2}$ The CCRF's initial focus was on advising undergraduates who were seeking competitive fellowships and grants (for example, the Rhodes Scholarships). Recently, the scope of its work has expanded to include supporting undergraduate research broadly through promoting and developing research opportunities within the university and beyond. While outreach to the CCRF was already underway, the 2015 and 2017 survey findings regarding student expectations for research opportunities at the university provided new urgency for building this relationship. The 2017 survey in particular demonstrated that undergraduates have limited opportunities to develop research skills-much less conduct original research-in the context of the college curriculum. Since the CCRF serves as a gatekeeper to undergraduate research opportunities, the library felt it was crucial to communicate the importance of developing research skills so that students are prepared to succeed when research opportunities arise.

Instead of approaching the initial meeting with the director of the CCRF with a list of services the library could provide, the library came prepared to demonstrate a shared understanding of the challenges faced by students hoping to conduct original research at the university. In this meeting, the library highlighted the 
high expectations student respondents had for research experiences with university faculty, along with their desire to develop research skills during their time at the university. This led to a broader discussion about the limited access to research opportunities for students in the humanities and social sciences, the need for additional research instruction in the college curriculum, and the scope of the library's current services in these areas.

By sharing its knowledge of student needs-grounded in survey data-along with possible strategies for addressing these needs, the library was able to demonstrate its appropriateness as a key partner in developing new undergraduate research programs and opportunities. A significant collaboration has emerged out of this partnership resulting in new programming and services, including the library hosting a week of programming focused on undergraduate research, a library research guide for Fulbright applicants, library office hours for CCRF staff, and training for the Chicago Summer Institute fellows, a new program supporting undergraduate research in the humanities and social sciences.

\section{Outreach to Faculty and University Administration}

In the past, reports on library surveys were typically posted on its public website, along with a brief executive summary and a description of areas for response. ${ }^{3}$ A news story on the library's website normally accompanied the release of the report, completing the cycle of reporting. Changes to the survey program in 2015 and 2017 resulted in findings that necessitated different strategies for publication.

Findings from the undergraduate survey were used to develop an article in the library's faculty newsletter, Libra, which used survey data to highlight the impact of instruction on undergraduate respondents' perceptions of their research skills. ${ }^{4}$ To expand upon outreach to faculty, additional talking points highlighting the survey findings were developed for the library's subject librarians, who are responsible for outreach to the departments and constituents they serve.

\section{Office of the Dean of Students in the College}

Following the success of outreach efforts with the College Center for Research and Fellowships, the library contacted the Office of the Dean of Students in the college. ${ }^{5}$ This office oversees undergraduate advising and support services, and works closely with college faculty on the curriculum. In preparation for a meeting with two associate deans of the college, a summary of findings and talking points detailing the library's role in supporting undergraduate academics were created using the data on coursework and research.

However, in this instance, the survey findings did not resonate with the audience as anticipated. It was clear that the associate deans were more interested in learning about library spaces, in particular the growing need for study space for undergraduates, than in the talking points that highlighted issues from the survey. Although the need for space was expressed by survey respondents, it was one of many that the library hoped to address in the context of this meeting. While more communication prior to the meeting could have facilitated more meaningful reporting on survey findings related to the topics of interest, the disconnect between the deans' interests and library's message demonstrate the importance of using data to illustrate how the roles of the library continue to shift to meet the changing needs of its constituents.

\section{Office of Institutional Analysis}

By contrast, discussing survey initiatives with new staff in the Office of Institutional Analysis laid the groundwork for what will hopefully be a productive partnership. The Office of Institutional Analysis, part of the Office of the Executive Vice President, coordinates and conducts analysis and assessment campus-wide. Personnel changes in this office necessitated building new relationships; the library used this opportunity to present its survey program in hopes of fostering a more robust data-sharing relationship than existed with previous personnel.

While the survey findings were not shared in the context of this initial meeting, the surveys themselves may have created new opportunities for collaboration and data sharing, as they contain data that parallel those collected by the campus through other survey instruments. As a result of this meeting, the library has been 
offered access to campus survey data to which it has never had access; in return, it intends to share survey findings, and hopes this office will partner to support future survey initiatives.

\section{Conclusion}

The library continues to draw on survey findings to inform outreach and strategic decision-making. Survey findings have already contributed to the development of a new Center for Digital Scholarship at the library and will be used to shape its services to the campus. Reports and presentation materials may be developed for specific collegiate divisions or majors since materials that directly relate to specific groups of students are more likely to resonate with campus faculty and administrators. Infographics using data or survey comments may help alumni or potential donors better understand the experience of undergraduates on campus and the library's role in supporting academics and the student experience. ${ }^{6}$ Finally, handouts or giveaways for prospective students highlighting survey findings may be helpful in promoting the role of the library in student life.

After creating and administering surveys of library users for nearly a decade, the University of Chicago Library shifted from designing surveys for internal use to engaging in outward-looking projects that centered on the experience of students in the broader university context. This shift in focus and strategy allowed the library to take an institution-wide perspective in its analyses and communication. Rather than producing high-level summary reports for library administrators, short, thematic reports were created focusing on student life and learning. These reports provided talking points for staff to use in their campus outreach, opening conversations which set the groundwork for new partnerships and expanded support for student needs. The library's survey findings continue to be mined for use in strategic communication with its various stakeholders as the library seeks to define and describe its ever-expanding role in supporting the university's mission.

-Copyright 2019 Elizabeth Edwards and Rebecca Starkey

\section{Endnotes}

1. "Chicago Center for Teaching," The University of Chicago, https://teaching.uchicago.edu/.

2. "College Center for Research and Fellowships," The College, The University of Chicago, http://ccrf.uchicago.edu/.

3. "Library Surveys and Reports," The University of Chicago Library, https://www.lib.uchicago.edu/about/thelibrary/surveys/.

4. "Libra (newsletter)," The University of Chicago Library, https://www.lib.uchicago.edu/about/newsevents/libra/.

5. "College Staff Directory," The College, The University of Chicago, https://college.uchicago.edu/about/college-staff-directory/.

6. The University of Chicago Library (@uchicagolibrary), "How Often Do Undergraduates Visit a Campus Library?” Instagram post, April 13, 2018, https://www.instagram.com/p/BhhgiCiBCMo/. 